Joanna White

\title{
'But isn't it the baby that decides when it will be born?': temporality and women's embodied experiences of giving birth
}

Contact details: University of the West of England, Glenside Campus, Blackberry Hill, Stapleton, Bristol BS16 1DD.

Word count: $6427+$ Biblio

$\underline{\text { Biographical details }}$

Joanna White is a Marie Skłodowska-Curie Fellow at the Department of Health and Social Sciences at the University of the West of England. Her most recent publications include: Assessing the performance of maternity care in Europe: a critical exploration of tools and indicators (BMC Health Services Research 2015, 15: 491) and Cross-cultural Bodies through Space (in K. Buccieri (ed). 2014. Body Tensions: Reflecting, Resisting, Transforming Time and Space. Oxford

: Inter-Disciplinary Press).

\begin{abstract}
Drawing on primary ethnographic research, this paper explores the intermeshing of different forms of time in contemporary childbirth, including the ways in which pregnant women are embedded within, informed by, and resist institutional categorizations of reproductive time. While each parturient who participated in my study described their own, unique relationships with birthing and time, all women employed clock-time to anchor critical phases of their labour. My analysis leads me to propose the concept of 'phenomenological time' as a means of capturing the embodied outcome of the complex, entwined relationships amongst the social and institutional time which each woman inhabits, her own individual, underlying physiology, and her ongoing psycho-social response throughout the birthing experience. My analysis suggests that further phenomenological studies of birth could lead to a more sophisticated understanding of the relationships between human beings and time including, alternative temporal forms such a multitemporality and 'reverse progression' during labour.
\end{abstract}

149 words 
Keywords: the body, embodiment, maternal health services, reproduction, time, temporality, phenomenology.

\section{'But isn't it the baby that decides when it will be born?': temporality and women's embodied experiences of giving birth}

Giving birth can be considered a unique, individual process. In western settings, birthing is influenced by the medical institution of the hospital and associated services, within which it became historically incorporated (McCourt and Dykes 2010). The implications of both the physical and temporal structuring of institutions in relation to power and status have been well documented (Goffman 1968, Foucault 1973, Zerubavel 1979), and the hegemonic, gendered nature of linear time, and its colonization of all social practice - including maternal health care - under a guise of objectivity and neutrality have been highlighted (Everingham 2002; Walsh 2010). Contemporary enactment of temporality within health institutions (the ways in which time is operationalized in relation to service provision), can be understood as an outcome of the systematization of linear time, resulting in new forms of discipline entwined with the power and status of certain professional groups, and activities structured around values such as efficiency, as well as medical knowledge and technology (Davies 1990, Downe and Dykes 2010). Hence Hilary Thomas's (1992) claim that as the gatekeeper of reproduction, medicine is also its timekeeper. As a result, it has been argued, women's birthing bodies became objects of surveillance and control in the obstetric units where childbirth predominantly occurs, ensuring measurable outputs (Davis-Floyd 1992). Recognition of this phenomenon and its negative outcomes has led to the relatively recent development of midwife-led birthing centres situated outside of hospitals, where waiting for 'natural' time is a prescribed practice (Walsh 2010). 
The social sciences have seen calls to re-conceptualize procreative time (Simonds 1992). While it has been posited that women's accounts of childbirth are saturated with a synthesis of or resistance to medical knowledge (Walsh 2009), recent experiential narrative analysis challenges this dichotomous analysis by examining ways in which women combine both medical institutional and other forms of social temporality in their birthing, resulting in complex forms of 'birthing time' (Maher 2008, p.129).

Drawing on seven first-time mothers' personal experiences, I examine in this paper the symbiotic relationships which exist between pregnant and birthing women and time, and demonstrate how these are inextricably linked both to clock-time, ever-present in wider society, as well as normative definitions of reproductive time mediated by medical institutions and staff. A number of women's descriptions of their individual, embodied experiences reveal a lived tension with time as structured within maternal care, and their resistance to the timeframes imposed upon them by this system. The birthing outcome is therefore a product of the intermeshing of external social (and medical) timescapes, women's agency, physiology, and psychological responses.

Following an explanation of my empirical approach, I will first explore how women's bodies are embedded within definitions of normative gestation and labour within the maternal health system, in which a form of 'time tricking' is undertaken by interventions such as labour induction, and women's responses to this. In the following sections, I analyse further examples of women's actual embodied reality, elaborating on the concept of 'phenomenological time' as the corporeal outcome of multiple intermeshings.

\section{Study background and method}


The findings I present were collected as part of an ethnographic study of cultural processes related to pregnancy and childbirth in Portugal and England. One element of the study involved closely following 18 women (ten in London and eight in Lisbon) from early pregnancy through to post-delivery. The two study sites were chosen for several reasons. Firstly, due to my biographical circumstances I have experienced pregnancy in both countries and cities, where I observed contrasting attitudes towards the reproducing body. While the Portuguese women I met consistently referred to the fearful prospect of labour pain and assumed they would require medical assistance (particularly epidural anaesthetic), the English women with whom I engaged invariably articulated their desire to have a natural birth and avoid medical intervention. Available aggregate data on the two countries, further, suggested that they provide contrasting cases: Portugal has one of the highest rates in Europe of both caesarean and other forms of intervention, such as vaginal and forceps delivery, England and the United Kingdom have substantially lower rates (cf. Euro-Peristat 2013) ${ }^{1}$. In England, the majority of women are cared for during pregnancy by midwives working within the National Health Service (NHS), ${ }^{2}$ with several, strategically timed visits to hospital obstetricians for surveillance scans. In Portugal ante-natal care (ANC) is provided by nurses and doctors at primary level, but numerous middle-class women who can afford to do so (or who have employer health insurance schemes), attend private obstetric clinics due to their desire to have a trusted individual accompany them through pregnancy. In many cases these obstetricians will be responsible for accompanying these same women through birth, within a public or private hospital. In England, public hospital births amongst low-risk women are midwife-led unless particular interventions are required; in Portugal midwife-led delivery is less common, partly because midwives have less status within hospitals. All of these differences suggested

\footnotetext{
${ }^{1}$ Not all interventions are routinely measured across all EU countries and regions. The Euro-Peristat project was established, in part, to address this shortcoming.

${ }^{2}$ The British National Health Service.
} 
that the contrasting childbirth 'cultures' in each setting, and their associated outcomes, were worthy of deeper exploration.

My research aimed to explore forms of embodiment experienced by women during pregnancy, delivery and the immediate post-natal period, and how these were influenced by personal relationships, belief systems, modes of authoritative knowledge, and the health services accessed. ${ }^{3}$ My study followed a phenomenological approach (Smith, Flowers and Larkin 2009; Walsh 2010), constructed around women's lived experiences of pregnancy and birth. I conducted a series of detailed interviews with each woman (minimum of two, maximum of six). Each interview was open-ended; participants were asked to describe what they felt was happening to their bodies in their own words, enabling them to lead the narrative exploration. ${ }^{4}$ Time emerged as a significant theme early in the analytical process. While the cases presented constitute a relatively small sample, ${ }^{5}$ they were explicitly selected to exemplify the tensions and complexity associated with (certain) women's lived experiences of time.

\section{A normative cycle and labour?}

In this first section, I introduce some of the personal narrative detail shared by study participants to explore the institutionally defined temporal structures within which women's bodies become embedded, from the moment of first interface with maternal health services.

\footnotetext{
${ }^{3}$ My study also included an investigation of the professional knowledge contexts, temporal, spatial and human resource organisation of health services and the influence of these on the views and behavior of maternal health practitioners. While doctors and midwives are often implicitly present in the narratives presented, further outputs from my research will focus on the views and experiences of health professionals.

${ }^{4}$ Pregnant women (all first-time mothers under the age of 35) were recruited through government ANC services and a process of snowballing; ethical permission was obtained from the respective health authorities at each location and all women provided informed consent for their participation. All interviews were recorded, transcribed and analysed using an iterative content analysis approach.

${ }^{5}$ It should be noted that all but two of the women in the sub-sample presented were from a white, middle class, professional background. Research with women from other backgrounds might elicit contrasting experiences.
} 
Rachel, ${ }^{6}$ from London, provided a stark example of this on describing her first meeting with a midwife:

Because I'm a bit of a maths geek maybe, as soon as I found out I was pregnant I went on the NHS website and I put in my dates and my cycle... which is quite a lot longer than the average person, but she [the midwife] wasn't interested in hearing about it being 34 days, and she said 'No, no, let's just put in 28 days' ... But I would have liked it to be as accurate as you possibly can...I know it's a minor issue...but she wasn't interested in that at all... she said, 'They'll adjust it at the scan if that's wrong'. But then, in my re-Googling they said they only adjust a scan if it's more than two weeks out. So they weren't interested... and so when someone asks me my due date I kind of give them this whole history!

In this situation both the pregnant woman and her carer were inextricably enmeshed within the cognitive ordering of time defined by the health system; both were dependent on the (technological) 'repertoire' available (Zerubavel 2002). The midwife could only apply the normative categorization of the menstrual cycle provided by the dating calculator: a 28 day menses. This led to a problem: Rachel's actual cycle could not be incorporated, leaving her feeling perturbed and confused about her due date; her desire for precision based on her own embodied temporal knowledge was ignored. Through this process the trajectory towards birth became not 'her time', but 'their time' (Thomas 1992, Adam 1995). Her apologetic tone ('I know it's a minor issue') suggests acceptance of a knowledge hierarchy and her body's absorption within the dominant system, but, as detailed later, the disjoint between her actual cycle and the way the system defined it created a tension which continued up until she gave birth.

\footnotetext{
${ }^{6}$ All names used in the article are pseudonyms.
} 
Despite the normative cycle presented to Rachel, the length of human gestation is consistently under-estimated; few women give birth on their technically predicted due date (Baskett and Nagele 2000, Westfall and Benoit 2004). Indeed, the reification of one date has been critiqued, with calls for a 'due range' rather than a defined twenty-four hour period, to reflect reality and alleviate anxiety amongst women (Saunders and Paterson 1991). Yet the allocation of a single date provides a vital illusion of control and precision for both medical practitioners and future parturients (Downe and Dykes 2010). Rachel's reference 'when someone asks me my due date' underscores the importance which the predicted date holds as a critical, anticipated (and much talked about) endpoint, not merely for pregnant women, but also family, friends and acquaintances. ${ }^{7}$ Many of the women in the study discussed their due date, including the probability of giving birth on this day, with increasing regularity as their pregnancy neared its end. Indeed, certain women described their awareness, from personal research, that often births fall outside the predicted date, and drew on family reproductive history as an indicator of whether their baby would be early, late or 'on time' (posing the question 'whose time?'). I observed an interesting amalgamation of scientific-technological and personal-hereditary time in women's understanding, both holding some meaning, neither considered definitive. This juggling of potential birth dates underscored the unknown quality of both the timing and the embodied experience of the future birth, which I will discuss below as 'phenomenological time'.

The systematic application of a standardized model of reproductive time with which Rachel was confronted is similarly identifiable in the clinical definition and management of labour, which is divided into three time-limited segments. The tool which established this convention is the Friedman curve, the development of which was based on research conducted with a

\footnotetext{
${ }^{7}$ One also thinks of the intense focus conventionally placed on the precise time at which a baby is actually born (as well as the newborn's birth weight); one could, perhaps, even term this, coupled with the interest in due date, a form of temporal obsession.
} 
sample of 500 American women in the 1950s. The Curve has been critiqued for the poor representativeness of the original sample and the failure to allow for individual variation, erroneously linking statistical and physiological normality (Rothman 1991). It has, further, been depicted as a means of imposing an artificial and sometimes risky constraint on women's labouring time (Scammell and Stewart 2014). Yet the Curve's temporal framework still underscores medical practice in many hospital settings. Cervical dilation and labour are assessed and appraised in relation to perceived progress against the Curve, with interruptions often considered as evidence of pathology and heightened risk (Simonds 2002). 'Failure to progress' - a suggestion of a temporal as well as material deficiency - is frequently used to justify intervention, including labour acceleration (Maher 2008; Scammell and Stewart 2014), often leading to a cascade of consequent measures. ${ }^{8}$ The Curve's continuing 'iconic' status in maternity units and within hospital protocols (Downe and Dykes 2010: 80) is explicable through its compatibility with a notion of regular and efficient throughput, valorized within such institutions. Moreover, its application to the definition of labour stages accentuates the quest for temporal certainty in clinical practice, which, scholars have argued, can dominate women's experiences, irrespective of individual physiology and family history (Simonds 2002; Downe and Dykes 2010).

My findings revealed a tension between the notion of defined chronological progression and lived experiences. In their post-delivery interview, some women voiced surprise at how long their labour had taken, a reality for which they had been unprepared and which therefore created some discomfort and anxiety. The belief that labour would be phased across a certain trajectory with a vividly present sense of ending framed women's experience and responses to situations which fell outside this paradigm. 'Too long' therefore became problematic. As one

\footnotetext{
${ }^{8}$ Clearly, under certain circumstances intervention is necessary to preserve the health of mother or baby, but this does not detract from the problematic association between a normative time definition and progress in every case.
} 
London-based respondent, Andrea, who experienced a 32 hour labour, ${ }^{9}$ detailed: 'The birth, the actual pushing and delivery was easier than I expected, and a lot less painful than I expected. But the length of the labour I wasn't quite expecting'.

In another example, again in England, Debra juxtaposed her embodied experience of a 24 hour labour, with how it was technically defined by the hospital: 'They only classed my labour as three hours - I think they only classify labour as starting once you are $4 \mathrm{~cm}$ dilated'. These descriptions reveal, in different forms, not only the complex intertwining of women's expectations and experiences, but their relationship with institutional definitions and the management of the temporal composition of labour. A further example of this is to be found in women's relationship with the acceleration of labour, which I will discuss in the next section.

\section{Time 'tricking' and acceleration}

A common phenomenon described by my informants was technical intervention to advance the onset or early progression of labour. This occurred in a variety of situations, when a woman was understood to have reached term and labour had not commenced, or labour was deemed to be advancing too slowly. Such measures can be conceptualised as 'tricking' time, a hastening to accelerate the birthing process. ${ }^{10}$ Techniques included the vaginal 'sweep', a physical manipulation whereby the amniotic sac membranes are separated from the cervix, releasing hormones and stimulating labour. This procedure, locally referred to as the toque

\footnotetext{
${ }^{9}$ Commencement of labour is defined here as the moment when a woman reported her first contraction.

${ }^{10}$ Perhaps Caesarean section can be considered the ultimate tricking, where the baby is extracted from the womb.
} 
('the touch') is extremely popular amongst obstetricians in Portugal - although its use is increasingly controversial. ${ }^{11}$

Critics of such intervention (except in cases of absolute necessity, such as emergency situations), have argued that such interference with the natural time of birthing bodies can lead to both fragmentation and alienation (Martin 1987; McCourt and Dykes 2010). The impact of the toque was described by Inês, a Portuguese participant, during her post-partum interview:

I was thirty-seven weeks, and my waters broke...just a little bit... the doctor said I had to go straight to hospital. They gave me a toque. No one told me what they would do. The doctor asked me to lie down and just did it. It was excruciatingly painful... I think they don't tell you beforehand so you can't escape (laughs)... It was very painful, horrible...I didn't know anything could be so painful...I then agreed to have the epidural because it was so painful and I couldn't cope ... What happened was very painful and invasive...It's invasive in that things are accelerated...you cannot expect to have a natural contraction, a normal one.

Inês emphasized not solely the pain (being unprepared for the toque may have caused particular discomfort) but the sense of invasion caused by the acceleration process. She was both physically and temporally disrupted. Her inability to cope with the melded pain of the toque and sudden onset of labour, led to further intervention. In this case, 'phenomenological time', the embodied temporal process of her labour and birthing, was an explicit product of intervention.

Induction is another method employed to accelerate labour, which can include the insertion of a vaginal pessary or gel, or the intravenous use of an artificial version of the hormone

\footnotetext{
${ }^{11} \mathrm{http}: / /$ www.paisefilhos.pt/index.php/destaque/3485-parto-quando-o-ltoquer-e-um-abuso-obstetrico, 'When the toque is obstetric abuse' (accessed 27 November 2015).
} 
oxytocin. A number of my Portuguese informants who received ANC from private obstetricians reported scheduling a date for delivery in advance in order to ensure the presence of their particular doctor. This arrangement unavoidably implied induction, and possibly a Caesarean section, in order for the birth to occur on the prescribed date. Sofia, one interviewee, detailed this process:

I think I was close to 38 weeks, she [the obstetrician] wanted to book the delivery date...I was a bit surprised. I said, 'But isn't it the baby that decides when it will be born?' Because... this is how it should be. And she said: 'Look, it's like this, Sofia, you know...the baby isn't doing anything, it's already fully developed, it's ready. Of course you can go into labour and come to the hospital and deliver...then it could be with any doctor. If you want me to be with you, then it is better to do it this way'... I resisted a bit and then she said: 'OK, let's wait one more week, but after 40 weeks I will not be responsible'. So I ended up doing a lot of walking to see if my belly would... Anyway, then when it was already 40 weeks and the baby had not been born... I ended up going in because I thought it was better, you know? ... Afterwards I talked to my friends and they said 'Oh, nowadays this [booking the delivery] is normal. You can't put your baby at risk'... So I arrived at the hospital in a totally normal state... without a single contraction. Like I was going on holiday, with my bag (laughs).

Sofia's hospital arrival felt to her like a comical dislocation: she felt like a suitcase-bearing tourist; her body showing no signs of readiness for birth. Spontaneous onset of labour was entirely abandoned as the obstetrician 'bent' time. The strategies of persuasion employed by the doctor are scientifically and ethically dubious; there is insufficient evidence for induction before 41 weeks of gestation without medical indication (cf. for example WHO 2011). The 
allusion to risk, which led Sofia to abandon her resistance, was, therefore, suspect. ${ }^{12}$ Sofia's submission resulted in induction followed by a Caesarean - a common pattern. There is increasing quantitative evidence regarding elevated caesarean rates at certain time periods, and the prevalence of induction and caesareans within particular institutions in Portugal, independent of client mix (Teixeira 2013). This underscores how time acceleration may be 'culturally' rooted in some settings as as much as scientifically linked to risk: certain doctors and institutions seemingly embrace the possibility of intervening in physiological processes more than others. In certain circumstances, therefore, obstetricians can be seen to be regulating reproductive bodies in both time and space to conduct their business more efficiently (Rothman 1991). ${ }^{13}$

Similar to Sofia, several of the London-based women in the study were confronted with the prospect of time acceleration through induction, and resisted this process. In the case of Rachel, detailed earlier, her individual cycle meant the system would inevitably define her as 'overdue' prematurely. Time became an increasingly dominant theme in her interviews as she approached the end of her pregnancy:

I really really feel strongly that I am going to be really late, and my biggest concern for labour is that I am going to end up being induced and that's when it gets to, like, you lose control of things, then it often leads to forceps, caesarean ...I already feel that they have got my week slightly out, by one week...I knew that this would become an issue at the end... The history of my family shows I'm already going to be two weeks late; having this extra week problem is going to be an issue for me. That's still my biggest issue.

\footnotetext{
${ }^{12}$ In some circumstances it is, of course, necessary to induce labour or carry out an emergency caesarean because of medical risk and clinical indication.

13 'Cultures' of birth and the associated management of time are variable both across and within countries. It should be noted that some hospitals in Portugal are taking active measures to promote normal birth. However, an independence of obstetric activity (hence marked variability between obstetric teams) is observable (White and Schouten 2014).
} 
Indeed, the final stage of her pregnancy, past 40 weeks, was characterized by an intense series of hospital appointments to discuss induction. She described this experience as 'the most stressed I've ever been in my life... I felt so harassed by the world with everyone trying to find out if I'd had the baby or not. I felt like I was forcing something that was not ready to happen, and I felt better if my body was ready to do it'. Here Rachel described her sense of isolation as she persevered in her goal of attaining a spontaneous labour; feeling pressurized not only by the maternal system but by family and friends who all, similarly, considered the due date she had been assigned as a signifier of the end of her pregnancy.

This sense of being 'forced' was shared by another London-based informant, Trudy, who was initially recommended induction due to an apparent pause in her baby's growth, which was identified in a scan late in pregnancy. Although this transpired to be an anomaly, one consultant's perception of risk at a particular stage in the baby's development meant that Trudy found herself subsequently obligated to attend numerous clinical consultations where she was regularly offered induction. She noted a difference amongst consultants in their attitude towards intervention; certain doctors were far more likely to pressurize her to accept induction (appointments with whom she described approaching with dread). This suggests that individuals within the same institutions may operationalize time in different ways. Similar to Rachel, Trudy juxtaposed the pressure she received with her own belief in spontaneous labour, founded on a sense of her - and her unborn child's - corporeal ability:

I just feel they are very pro-induction...it's no big deal at all. But to me, it's not something I want, so I have to keep saying no, and hope that baby keeps coming on his own...I would like to give the baby the best chance to be able to cope with the whole labour, as opposed to being forced or evicted out! I'm $34 \ldots I^{\prime}$ ve been working with this (body) for so many years! It doesn't matter - you still get the pressure. 
The terms used by Rachel and Trudy ('forcing', 'evicted') and Sofia's reference to 'how it should be', all evoke the medical profession's tricking of their reproductive time as a form of pressure. This dominant temporal framework operated against, and conflicted with, the women's own sense of when they and their baby were 'ready' to give birth, a tension which echoes findings from other studies (Westfall and Benoit 2004; Gatward et al. 2010).

Trudy continued resisting the pressure for induction until she went into labour spontaneously. However, on arrival at hospital her progression was considered slow:

I was told if I was not delivered by 8am in the morning - when the midwife goes off shift - then I'd need to decide what to do - whether to have the membranes ruptures- I felt I would have to make a decision. I would have to move to the ante-natal waiting area or be ruptured...so we waited, had a shower, and then I went out to the [hospital] stairs and did the stairs, from the bottom to the top...from the ground floor. I don't know how it was...we just did the stairs and the contractions increased...You know, you read that you need to be active to get the intensity and things... and it was taking a long time...There were people there that we killed the time with, and...one of the mothers, said you can have a shower, that can get things going, you can eat pineapple' ...and then after that, she was like 'you can do the stairs' so we went out to do the stairs.

Trudy's description captures effectively the ways in which both she and the health professionals were located within a system with clearly defined temporal and spatial boundaries (the imminent $8 \mathrm{am}$ midwife shift change marking a key decision-making point; the requirement to be moved to a different location if she did not accept induction). Interestingly, despite resisting hospital-based induction, Sofia, Rachel and Trudy all took independent measures to hasten labour, attempting their own, supposedly natural time- 
tricking. This implies their acceptance of the principle of speeding up the process as long as it was done 'naturally'. Rachel described taking long walks (also Sofia's strategy) and eating spicy food while Trudy was advised on different measures to advance her labour by a fellow parturient, the woman she, appropriately, described herself as 'killing time' with.

These autonomous activities to bring on /hasten labour symbolise women's agency in managing their own bodies, as well as their willingness to accelerate their own physiological processes, once they considered themselves ready. The women's behaviour here is inextricably linked to the weight of their knowledge, as well as the active pressure they have experienced, associated with the fact that they have been defined as ready to give birth by the medical system. The 'phenomenological time' whereby they finally birthed, was inextricably linked to the institutional temporal schema to which they had been exposed. Recent anthropological analyses of time have uncovered how the abstract measurement of time acts as a universal measure of value, which can conflict with concrete experiences; representations of science and technology, for example, harness human time to external non-human rhythms (Bear 2014). As my study findings reveal, the anthropological study of childbirth provides a rich canvas for exploring the tensions inherent in linear representations of time and women's sense and experiences of their own body. Indeed, the two become conflated in complicated ways. The example of my informants' autonomous time tricking in labour is an intriguing example of this phenomenon. It may be that non-human rhythms become blended with human rhythms, and archetypal 'natural' time in the birthing process may not fully exist.

\section{Time intertwined}

I will now elaborate on the concept of phenomenological time, the unique embodied birthing experience of each woman, drawing on further narrative examples. Debra's experience of her 
extended labour provides a telling case. As she recounted, her waters broke several days before her due date and, following some hours spent at home, she arrived in hospital at 2am after the onset of painful contractions. Her labour then progressed slowly.

I was in labour and just, kind of, dealt with it...By lunchtime they said 'ok, your baby's coming. She'll be here by about $1.30 \mathrm{pm}$; you're dilating'. It seemed like I was dilating increasingly. And then nothing was happening. 3 o'clock came, and they were telling me I should push....3 in the afternoon...still there...3 in the afternoon, I started to vomit everywhere, and get really hot, and I said 'I think I'm ill, I think I need to see a doctor', and they said, 'no, no, you're going into transition labour...and nothing happened... I was pushing...they were saying, you know, it's coming, you're 9 centimetres now, the baby should be here any minute'. And it just went on and on. And eventually it got to, like, 8 o'clock in the evening and everything had slowed down a bit... And then they went off shift and, yeah...I think I found that quite distressing, cos I'd really hoped that I was going to be with the midwives. I just wanted them to be there... and a midwife came down from the labour ward... and she checked me and she said 'you're only 5 centimetres dilated, you need to come upstairs and be induced'... and it was, like, awful, like everything had been turned upside down... and it started to feel like a bit of a nightmare.

Debra's punctuation of various experiential phases with the use of clock-time, was a common feature of women's accounts of labour. The midwives' decision to project a specific time for the arrival of the baby - again, the quest for precision - though possibly aimed at encouraging Debra - created unrealized expectations and heightened tensions as the 'promised' progress failed to materialize. The negative impact of trusted carers being replaced 
by a new midwife with a new prognosis is vividly captured: 'everything had been turned upside down'. ${ }^{14}$

The description of the midwives ending their shift emphasises how institutionalized time runs alongside - and at odds with - the physiological process; the hand-over of staff causing a palpable disruption. Similarly, Andrea, another study participant in London who experienced a long, difficult labour, described herself measuring her perceived lack of progress: '....at one point I was looking at the clock, and thinking 'oh God, the next shift of midwives is going to start'. The presence of the clock in the delivery room, visible to the labouring woman, is a highly symbolic focal point, and its association with staff turnover contributed to Andrea's anxiety about her labour.

Adam (1995) argued that the more intrusive maternal care assistance is the more women are forced to oscillate between the all-encompassing 'body time' of their labour and the imposed, rational framework of clock-time. Indeed, much scholarship juxtaposes a primal, 'archetypal', natural time existing between mother and fetus, and an externally inflicted temporality (Fox 1989, Adam 1995, Munro and Belova 2008). While one may wonder how situations such as that faced by Andrea would have evolved without the presence of a clock and time-segmented care, my research findings suggest, again, that a dichotomous analysis between imposed, linear time and a form of natural time in birth may be too simplistic. An alternative proposition is that women's socially conditioned understanding of time, as well as the location or institution where childbirth occurs, inevitably mediate their lived experiences. Hence, as Adam (1995) acknowledges, different forms of time interpenetrate and inform each others' meanings. The outcome of these processes are phenomenological time: the ensuing lived embodied outcome of complex social (and psycho-social) and physiological inter-

\footnotetext{
${ }^{14}$ Debra was subsequently induced and then had an emergency caesarean at 4.30am; it transpired that an undiagnosed infection was another aspect of her case which had affected her labour.
} 
relationships. Debra's case of stalled labour provides a vivid example. Following her birth a senior midwife provided her with a possible explanation:

They said your cervix may have dilated and then popped back again, which apparently can happen...going through my notes afterwards the midwife manager said...that maybe the stress of them [the midwives] going off shift, you suddenly just went back... She said it happens, she said you will read everywhere that that's impossible, but she said as a midwife, she said - she is a midwife with tons of experience - she said that it does happen [labour regression].

The embodied reality of labour going backwards through cervical 'regression' or 'reversal', and the factors influencing this, appear to be seldom discussed outside of midwifery circles, with only limited research conducted on this phenomenon. ${ }^{15}$ Debra's midwife suggests an intriguing silence about this phenomenon within medical discourse. Does this 'reverse progression' - time seemingly going backwards - represent too complex a challenge to dominant understanding of labour time as a process always moving purposively and irrevocably forward?

Clearly, despite labour remaining in both popular perception (and, as described earlier) medical representation as a time-segmented process towards progress, the reality can be distinctly different. Women are clearly unprepared for this experience. Andrea described her surprise at the embodied reality of her labour, which 'froze' at certain points:

I wasn't expecting it to start and stop, I didn't realise that labour can slow down once you're in it, I didn't realise that contractions could stop once you'd had them for 12

\footnotetext{
${ }^{15}$ British midwife, personal communication. See Haus and Bailie (1978), also https://uk.groups.yahoo.com/ neo/groups/cervicalreversalUK/info (accessed 27 $7^{\text {th }}$ November 2015); $\underline{\text { http://www.birthworks.co.za/ }}$ articles/cervical-reversalregression. (accessed $27^{\text {th }}$ November 2015). Knowledge of the concept of labour regression has also been identified in other cultures. See http://inamay.com/going-backwards-the-concept-ofpasmo/ (accessed 27 $7^{\text {th }}$ November 2015).
} 
hours, that they can then stop or slow completely down. I never knew any of that. So that was like a shock.

Before concluding, I will share the case of a Portuguese study participant who opted for homebirth, in line with her aim to have a natural birth and avoid medical intervention. Homebirth is a minority, risky choice in Portugal as it is not supported by state health services. Luisa described the end of her long labour which had extended over twelve hours overnight:

I walked around... and then there was this constant feeling...I remember, that it was going to take a long time, and everything was going very slowly and the waves of pain...it was eleven in the morning, I just know that it was eleven in the morning...The midwife said: 'Take a walk in the garden with Pedro [Luisa's partner]. Go for a walk'. And I went and then I thought, but did not tell anybody (laughs): 'Ok, I'm going to the hospital...'. I was done. I was very tired... I was exhausted. I was like: 'Ok, this is not happening... I'm going to go to the hospital and ask for an epidural and have this baby'. I was still in dialogue with myself...I knew that was not what I wanted...giving up, in a way...I would not communicate this to those who were with me without being absolutely sure... it had to be a final decision.

After that what happened is that I wanted to throw up. And then, kneeling and vomiting there made me think: 'No...ok, I'm going to go through with this. What will they do at the hospital? Give me an epidural. I'll go to a horrible place; it will be worse. I'm staying here'. After that it was really quick. 
Luisa's interior dialogue is an independent weighing up of her options; no external agent or technical appraisal participated in her decision of how to proceed. ${ }^{16}$ Following her contemplation a physical shift occurred, most likely the transition phase of labour, resulting in a complete change in pace. It is doubtful whether in a Portuguese (or any other hospital setting), this temporal autonomy - taking of time - would have occurred without some assessment related to progress and cervical dilation.

Initially Luisa felt time passing extremely slowly, marked by surges of pain as the contractions ebbed and flowed. Such paradoxical and fluctuating experiences of labour time have prompted the suggestion that physiological birth, with its cyclic flow of contractions, followed by pauses, are equivalent to the temporal dimensions identified in music (McFarlane 1998), in which the explicit present recalls and echoes the memory of the implicit, immediate past (Downe and Dykes 2010); a premise which echoes the notion of experiential multitemporality (Serres 1982).

Yet, while these various effects may co-exist within women's lived experiences, similar to the cases described above, Luisa simultaneously observed clock-time ('eleven in the morning'). Linear time anchored the situation; all manner of complex sensations occurring around these points. Similar to other narratives presented, rational clock-time played a vital role in punctuating the intense experiences of labour. Again, even in a case where a natural birth was sought out, what resulted was a product not only of the woman's physiology (without medical intervention) but mediated through her consciousness of clock-time and her internal dialogue about the (time) pressure she would receive for medical intervention if she went into hospital; all of these elements were conflated in her phenomenological time: her lived experience of labour.

\footnotetext{
${ }^{16}$ Luisa hired a private midwife to attend to her at home. This individual remained a background figure throughout the narrative.
} 


\section{Conclusion}

This paper delineated the intermeshing of different forms of time in contemporary childbirth. Birthing and time can be seen to be interlinked to embodiment and psycho-social elements in complex ways, and to flow differently for each parturient. The temporality of maternal care institutions, much of which echoes the linear timescapes present in wider social practices, provides an essential, inescapable element of women's experiences of birth. The normative time associated with gestation and labour was transmitted to women through maternal health services and informed their embodied experience. Even in narratives where women described their intense, unique physical experience of labour as ebbing and flowing, and focused on their own bodies, clock-time punctuated these descriptions, anchoring the process. The concept of phenomenological time can be seen to incorporate the embodied outcome of the interpenetration of different temporal elements, and is distinguishable from the reified, yet perhaps unattainable 'natural time', which is still implicit in the idea of natural birth (while many women may go into labour spontaneously, do any ever give birth with no reference to clock-time?).

Further phenomenological exploration of birth, including closer examination of spontaneous physiological labour and birth outside of institutional settings may lead to more sophisticated understanding of the symbiosis between human beings and time, the distinct, inter-linking factors influencing women's embodied temporality and also the possibility of alternative temporal forms such as multitemporality and 'reverse progression' during labour, all of which have received limited attention.

Some of the findings presented here have important implications for maternity care, such as the definition of a temporal range for birth (instead of due date), which can incorporate 
women's known reproductive cycle, and the re-assessment of definitions of normative labour and the labour process, in order to re-shape women's expectations of the temporal forms which labour may take. That cervical dilation can, in some cases, regress, dramatically challenges the conventional conflation of 'progress' with the passage of time and merits further exploration.

The maternal health care system in Portugal represents a more extreme example of medicalization than England, which may explain why women's agency is less apparent or, one could say, less successful in the Portuguese hospital birth narratives presented. However, despite the maternal health systems in the two countries being structured differently, I observed surprisingly similar patterns in terms of the way in which institutionalized time tricking is applied as a matter of course within medical settings, women's resistance to these processes and their associated application of 'natural' measures to speed up their own birthing through their own, autonomous time-tricking.

\section{$\underline{\text { Acknowledgements }}$}

My sincere thanks to all of the women who participated in the study. The research was funded by the EU Marie Curie Welcome II Programme and the Portuguese government. Participation in the ASA conference where the original version of this paper was presented was made possible by the Portuguese Foundation for Science and Technology (FCT) through UID/ANT/04038/2013 support. Many thanks to the Centre for Research in Anthropology (CRIA-IUL), Lisbon and King's College, London where I was affiliated during the course of the study and to the Health Foundation Trust which facilitated contact with pregnant women in London, and the Regional Health Trust which facilitated access to women in Lisbon. 


\section{Bibliography}

Adam, B. 1995. Timewatch: the social analysis of time. Cambridge: Polity Press.

Baskett, T.F. and Nagele, F. 2000. Naegele's rule: A reappraisal. British Journal of Obstetrics and Gynaecology 107: 1433-1435.

Bear, L. 2014. Doubt, conflict, mediation: the anthropology of modern time. Journal of the Royal Anthropological Institute, 20 (S1): 3-30.

Beck, C. 1994. Women's temporal experiences during the delivery process: a phenomenological study. International Journal of Nursing Studies 31 (3): 245-252.

Davis-Floyd, R. 1992. Birth as an American rite of passage. Berkeley, CA: University of California Press.

Davies, K. 1990. Women, time, and the weaving of the strands of everyday life. Aldershot: Gower Publishing Company.

Downe, S. and Dykes, F. 2010. Counting Time in Pregnancy and Labour. In Childbirth, Midwifery and Concepts of Time, (ed.) C. McCourt, pp. 61-83. Oxford: Berghahn.

Eriksen, T. 2001. Tyranny of the Moment: Fast and Slow Time in the Information Age. London: Pluto Press.

Euro-Peristat Project with SCPE and EUROCAT. 2013. European Perinatal Health Report. The health and care of pregnant women in Europe in May 2010. www.europeristat.com

Foucault, M. 1973. The Birth of the Clinic: An Archaeology of Medical Perception. New York: Pantheon.

Fox. M. 1989. Unreliable Allies: Subjective and Objective Time, in F.J.Forman and C. Sowton (eds.) Taking Our Time, Feminist Perspectives on Temporality. Oxford: Pergamon.

Everingham, C. 2002. Engendering Time: Gender equity and discourses of workplace flexibility. Time \& Society 11: 335-351.

Gatward, H., Simpson, M., Woodhart, L., and Colleen Stainton, M. 2010. Women's experiences of being induced for post-date pregnancy. Women and Birth 23: 3-9.

Goffman E. 1968. Asylum: Essays on the Social Situation of Mental Patients and other Inmates. Harmandsworth: Penguin.

Grosz, E. 1995. Space, time and perversion: the politics of bodies. St. Leonards, NSW: Allen and Unwin.

Haus, M. and Bailie, P. 1978. Reversal of Active Labor: A Case Report. SA Mediese Tydskrif, 16 September 1978.

Maher, J. 2008. Progressing through labour and delivery: Birth time and women's experiences. Women's Studies International Forum, 31: 129-137. 
Martin, E. 1987. The woman in the body: A cultural analysis of reproduction. Boston, MA: Beacon Press.

McCourt, C. and Dykes, F. 2010. From Tradition to Modernity: Time and Childbirth in Historical Perspective. In (ed.) C. McCourt, Childbirth, Midwifery and Concepts of Time, 1736. Oxford: Berghahn.

McFarlane,T.J. 1998. The nature of time. http://www.integralscience.org/abouttime.html. Accessed 28th September 2015.

Munro, R. and Belova, O. 2008. The body in time: knowing bodies and the interruption of narrative. The Sociological Review, s2 Vol 56: 85-99. Special Issue Re/knowing Bodies.

Rothman, B.K. 1991. In Labor: Women and power in the Birthplace (revised ed.). New York: W.W. Norton.

Saunders, N. and Paterson, C. 1991. Can we abandon Naegele's Rule? Lancet 9 (8741): 600601.

Scammell, M. and Stewart, M. 2014. Time, risk and midwife practice: the vaginal examination. Health, Risk and Society 16 (1): 84-100.

Serres, M. 1982. Hermes: Literature, Science, Philosophy. Baltimore: John Hopkins University Press.

Simonds, W. 2010.Watching the clock: keeping time during pregnancy, birth, and postpartum experiences. Social Science \& Medicine 55 (49): 559-570.

Smith, J.A., Flowers, P. and Larkin, M. 2009. Interpretive Phenomeological Analysis: Understanding Method and Application. London: Sage.

Teixeira, C. 2014. Factors affecting caesarean rates: findings from a cohort in Northern Portugal in J. White and M. Schouten (eds.). 2014. Normal Birth: experiences from Portugal and Beyond/O Parto Normal: experiências de Portugal e além-fronteiras. Braga: CICS and Lisbon: CRIA.

Thomas. H. 1992. Time and the Cervix. In Time, Health and Medicine, (ed.) R. Frankenberg, 56-67. London: Sage.

Walsh, D. 2010. 'Waiting on Birth: Management of Time and Place in a Birth Centre. In (ed.) C. McCourt, Childbirth, Midwifery and Concepts of Time, 126-144. Oxford: Berghahn.

Westfall, R.E. and Benoit, C. 2004. The rhetoric of "natural" in natural childbirth: childbearing women's perspectives on prolonged pregnancy and induction of labour. Social Science \& Medicine 59: 1397-1408.

White, J. and Schouten, M.J. 2014. 'Normal birth as a cultural phenomenon' in J. White and M. Schouten (eds.). 2014. Normal Birth: experiences from Portugal and Beyond/O Parto Normal: experiências de Portugal e além-fronteiras. Braga: CICS and Lisbon: CRIA.

WHO. 2011. WHO recommendations for Induction of labour. Geneva: WHO

Zerubavel, E. 1979. Patterns of Time in Hospital Life. Chicago: University of Chicago Press. 
